\title{
Three new species of Inseliellum (Diptera: Simuliidae) from Polynesia
}

\author{
DOUGLAS A. CRAIG
}

Department of Biological Sciences, University of Alberta, Edmonton, Alberta, Canada, T6G 2E9;

d.craig@ualberta.ca

\section{Table of contents}

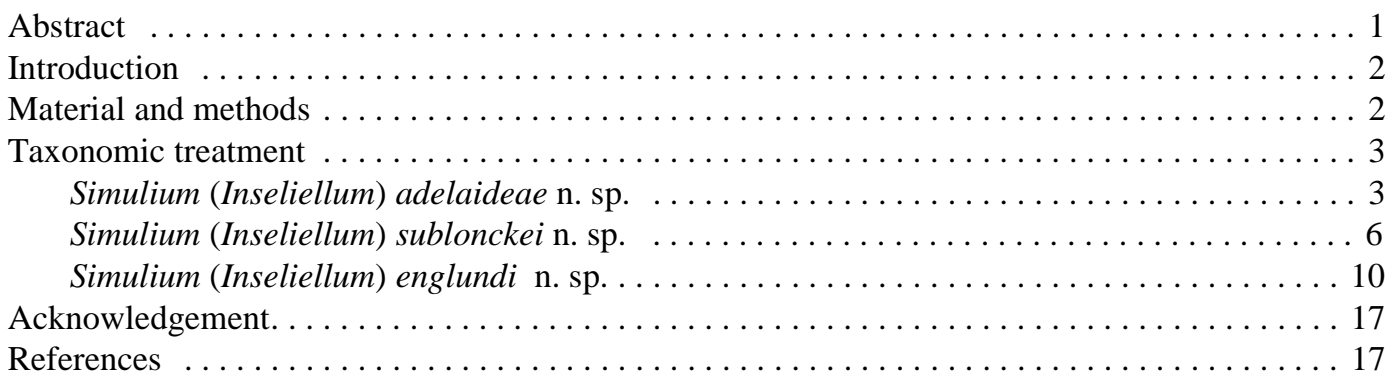

\begin{abstract}
Three new species of the simuliid subgenus Inseliellum are described. Simulium adelaideae, from Tahiti, appears to be closely related to the hirticranium subgroup and may constitute the sister species of that taxon. Simulium sublonckei, also from Tahiti, is the sister species of S. lonckei plus $S$. joyae. The third new species, Simulium englundi, from the Marquesas Islands, is closely related to S. gallinum.

The Tahitian species are both from higher altitude localities and bring the number of known species for that island to 31. There are now 10 species known from the Marquesas islands, for a total of 51 species in Inseliellum.
\end{abstract}

Key words: Simuliidae, Inseliellum, new species, Tahiti, Marquesas 
Craig (1987) estimated that only $75 \%$ of species of Inseliellum in Tahiti had been described. At that time, only 13 nominal species were recognized, so the upper estimate would have been some 17 species. Ten years later, however, 23 species were known from Tahiti, with almost all new species occurring in higher altitude and specialized habitats, such as cascades and grottos (Craig 1997), but the rate of discovery had slowed even with intensive collection. Attempting another estimate of the number of simuliid species in Tahiti, Craig (1997) speculated that 27 would be the final number. However, Craig and Joy (2000) described another five new species from Tahiti, for a total of 29, noting that some species were probably complexes. With species from Micronesia, plus those from the Cook Islands, Austral Islands and the Marquesas, there were then 48 known species of Inseliellum.

While earlier estimates of species numbers proved to be incorrect, the basic taxonomic groupings within Inseliellum continued to hold (Craig 1983, Craig and Currie 1999, Craig et al. 2001). That is, the Micronesian species (S. trukense, S. guamense) are basal with the next most basal clade containing the Cook, Austral and Marquesas Island species. In the Society Islands, $S$. malardei is basal to all others, with then a clade of species related to $S$. tahitiense, and one (castaneum group) containing the majority of cascade-dwelling species and the oviceps group. Some of the recently described species (Craig and Joy 2000) form new clades within established groups (e.g., the hirticranium subgroup of the castaneum group), but others have obscured delimitation of the original groups proposed by Craig and Currie (1999), and Craig and Joy (2000). This trend is continued with the new species described herein. In large part this refining of taxonomic limits results from availability of extensive collections made in recent years (e.g., Craig 2001) that allow detailed comparison.

With the three new species described here, the total now for Inseliellum is 51, including 10 for the Marquesas islands and 31 for Tahiti.

\section{Material and methods}

Description of species based on single specimens (e.g., S. adelaideae) is fraught with pitfalls, as previously noted by Craig $(1987,1997)$. Here, only specimens that are clearly unique in a suite of characters are assigned species status. This rationale has, in large part, been borne out. Other unique specimens, recognized as species, have eventually had more material collected, albeit in some instances, decades later (e.g., S. evenhuisi. Craig 1997).

For other material that might be considered just a variant of a known species, such as S. dussertorum before it was recognized as separate from S. oviceps (Craig 1987, 1997), consistent recognition of material from multiple localities is generally taken as an indication of species status. Simulium sublonckei with considerable material available, and from 
more than one locality, is such a species. For $S$. englundi, which is markedly similar to $S$. gallinum, there were distinguishing morphological features in almost all stages available. Figures 13 and 14 of S. lonckei and S. joyae respectively, and Fig. 21 of S. gallinum, are provided for comparative purposes.

Methods (mounting and illustrations) for treatment of adults, pupae and larvae follow those of Craig (1997). Terms for morphological structures and format of taxonomic descriptions follow those of Craig et al. (2003).

Material is deposited in the following institutions and is indicated as, for example (larvae. DAC, ROM):

BPBM Bernice P. Bishop Museum, Honolulu, Hawai ${ }^{1}$, USA.

CNCI Canadian National Collection of Insects, Arachnids and Nematodes, Biological Research Division, Centre for Land and Biological Resources Research, Agriculture Canada, Ottawa, Canada.

DAC Personal collection. D.A. Craig, Department of Biological Sciences, University of Alberta, Edmonton, Canada.

ROM Centre for Biodiversity and Conservation Biology, Royal Ontario Museum, Toronto, Ontario, Canada

\section{Taxonomic treatment}

\section{Simulium (Inseliellum) adelaideae $\mathbf{n} . \mathbf{s p}$.}

(Figs. 1-6, 27)

Types

Holotype

Larva: early penultimate instar as slide mount. Label data: "Simulium (I) adelaideae. TAHITI. Above Lac Vaihiria, alt. 643 m. S17 40.26’ W149²5.33’. 30.viii.1998. Coll. D. A. Craig. HOLOTYPE. \#16523" (BPBM).

\section{Diagnosis}

Larva: head markedly brown and yellow, head spot pattern negative; apices of hypostomal teeth forming straight array with only median tooth protruding; postgenal cleft essentially absent; posterior arms of anal sclerite completely encircling base of posterior proleg, markedly so ventrally; accessory sclerites extended anteromedially

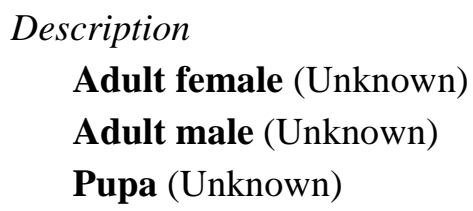




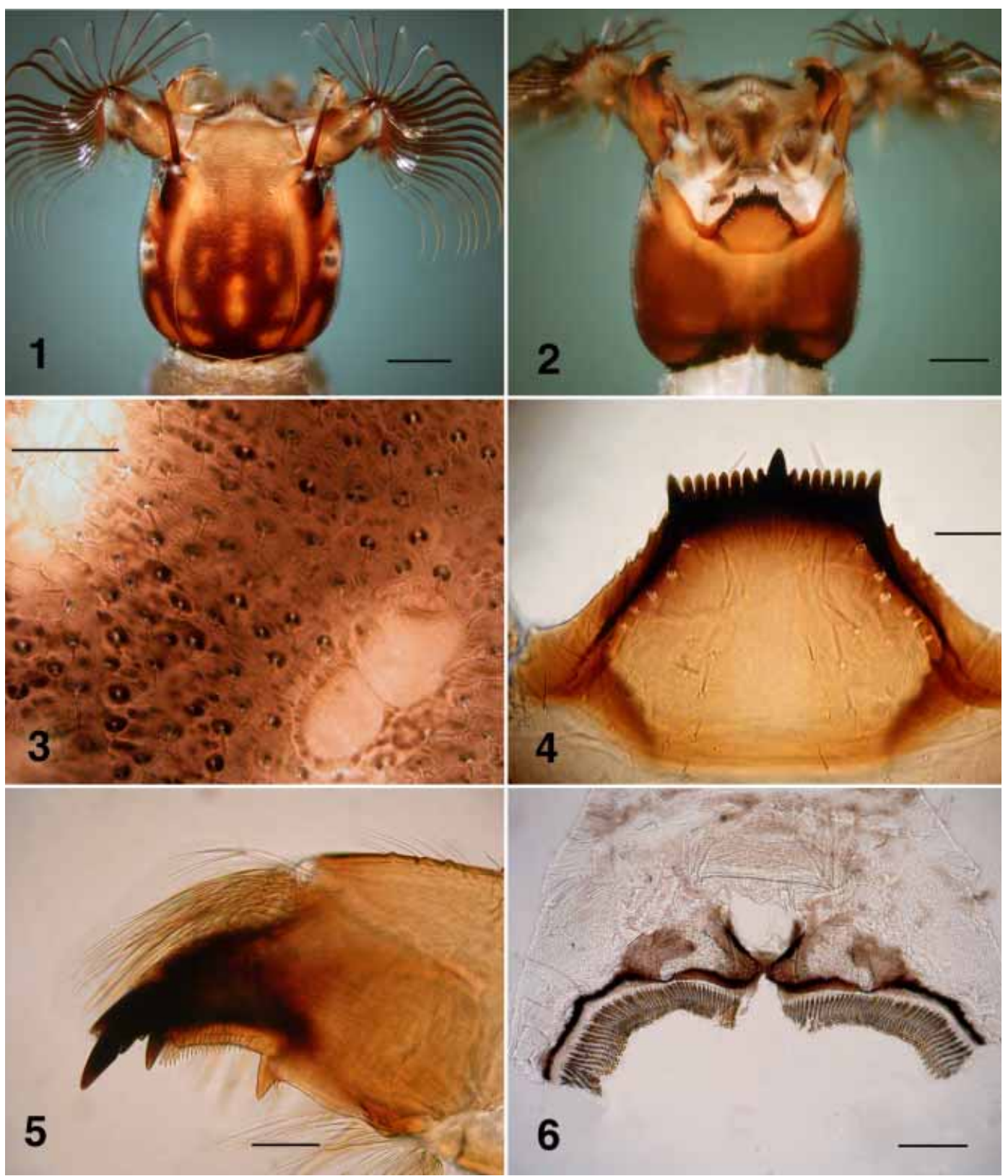

FIGURES 1-6. Simulium adelaideae, penultimate instar larva. 1. Dorsal view of head. Scale bar = $0.25 \mathrm{~mm}$. 2. Ventral view of head. Scale bar $=0.25 \mathrm{~mm}$. 3. Head cuticle and setae, showing corrugations and raised setal bases. Scale bar $=0.05 \mathrm{~mm}$. 4. Hypostoma. Scale bar $=0.05$. 5. Mandible. Scale bar $=0.05 \mathrm{~mm}$. 6. Anal sclerite. Scale bar $=0.2 \mathrm{~mm}$.

Larva (based on one mature penultimate instar larva)

Body: total length $5.8 \mathrm{~mm}$; colour evenly greyish brown. Head (Figs. 1, 2): width 0.9 $\mathrm{mm}$, length $1.1 \mathrm{~mm}$; distance between antennal bases $0.51 \mathrm{~mm}$; head spots yellow, anterior 
of apotome pale yellow, remainder of cuticle rich brown; head margins convex, markedly so posteriorly; cervical sclerites fused to postocciput; setae numerous, length normal, sockets raised; cuticle markedly corrugated and rugose (Fig. 3). Antenna: longer than labral-fan stem; total length $0.47 \mathrm{~mm}$; distal article $0.13 \mathrm{~mm}$; whole antenna markedly dark brown. Labral fan: fan stem light brown, hairy distally and posteriorly; 23 dark brown rays, $0.89 \mathrm{~mm}$ in length; 5-6 posterior rays finer than others, medial rays $0.02 \mathrm{~mm}$ wide; microtrichia 0.5 ray width, pattern of longer microtrichia with 7 subequal then two markedly smaller microtrichia between; ray apex extended. Postgenal bridge (Fig. 2): 7 times longer than cleft depth; yellow anteriorly. Postgenal cleft: essentially absent, except for small V-shaped notch. Hypostoma (Fig. 4): 17 teeth; prominent median tooth extended beyond others; sublateral teeth increased slightly in length laterally, but with tips in straight array; lateral teeth slightly longer than sublateral teeth; 1 paralateral tooth; 5-6 lateral serrations; 6 hypostomal setae per side. Mandible (Fig. 5): only apical tooth well developed; spinous teeth markedly developed; serration prominent, basal sensillum distinct. Maxilla: lobe rounded; palpus 4 times longer than width—markedly developed (Fig. 2). Mandibular phragma: extended ventrally to 0.3 depth of maxillary base. Abdomen: slightly amphora-shaped; posterodorsal cuticle not tuberculate, but with clear ovoid tubercles lateral of anal sclerite; sensilla trichoid, slightly elongated, sockets normal. Anal sclerite (Fig. 6): well developed and darkly pigmented; median region expanded laterally, well pigmented, markedly hirsute with distinct clear sockets; accessory sclerites extended anteromedially almost to anterodorsal arms of anal sclerite; ventral arms extended around posterior proleg, substantially so ventrally. Posterior proleg circlet of hooks: with 110 rows of hooks, 15-16 hooks per row. Rectal papillae: three, with small basal papillae.

\section{Additional material examined}

None.

Etymology

Named after Adelaide, daughter of D. Joy and F. Elliott.

\section{Comments}

Superficially similar to $S$. cataractarum larvae, S. adelaideae differs noticeably in its enhanced head pattern and is perhaps the most colourful of all Inseliellum larvae, matched perhaps only by the head pattern of larval S. arlecchinum (Craig and Joy 2000). The number and arrangement of hypostomal teeth is similar to that seen in the hirticranium subgroup (Craig and Joy 2000) and is reminiscent of that seen in the oviceps group. The virtually absent postgenal cleft is also shared with the hirticranium group, as is the development of the anal sclerite. The apical teeth of the mandible are also similar to those of $S$. hispidum. Absence of tubercles on the abdominal cuticle is shared with larvae of S. cataractarum and the hirticranium subgroup, except that $S$. adelaideae possesses tuberculate 
cuticle just anterior of the anal sclerite. Although sharing numbers of synapomorphic traits with the hirticranium subgroup, S. adelaideae does, however, not show the diagnostic elongated head setae possessed by larvae of that taxonomic segregate. Still, with its complement of character states, $S$. adelaideae will no doubt, after more detailed phylogenetic analysis, be shown to be related to $S$. cataractarum and probably basal to the hirticranium subgroup.

The type locality of $S$. adelaideae is the highest stream on the road that continues past and above Lac Vaihiria and through a tunnel to emerge in the Papenoo Valley. Fed by a small cascade the stream flows though dense vegetation before emerging (Fig. 27) into sunlight, then crosses the road to plunge some $200 \mathrm{~m}$ down into the Lac Vaihiria Valley. With air temperature at $21^{\circ} \mathrm{C}$, water temperature was $18^{\circ} \mathrm{C}, \mathrm{pH} 8.4$, and conductivity 50 $\mu \mathrm{S}$. Water velocity was $76-98 \mathrm{~cm} / \mathrm{s}$ and depth ca. $30 \mathrm{~cm}$.

This small stream is unusual in the complement of species collected. Cascade-dwelling species ( $S$. cataractarum, $S$. dussertorum, S. fossatiae, S. oviceps) probably originate from the cascade immediately upstream. Larvae of $S$. lotii and S. malardei, typical of smaller streams at lower altitude, were markedly larger than normal. Simulium cheesmanae adults were captured while trying to bite the author.

\section{Simulium (Inseliellum) sublonckei $\mathbf{n}$. sp.}

Figs. 7-12, 15, 28

Types

\section{Holotype}

Larva: Last instar: in alcohol. Label data: "Simulium (I) sublonckei Craig. TAHITI, Vaitamanu Valley, 2nd cascade, alt. 325 m. S17 $37.51^{\prime}$ W149 $26.20^{\prime}$. 12-xi-2000. Coll. D. A. and R. E. G. Craig. HOLOTYPE \#16525" (BPBM).

\section{Paratypes}

Larvae: Penultimate instars in alcohol. Label data as for Holotype, but with "PARATYPE" (larvae. CNCI, BPBM, DAC, ROM).

\section{Diagnosis}

Larva: body densely covered dorsally with dark brown, ovoid tubercles, with sharp delimitation laterally and pale median line on thorax; head markedly convex posteriorly, not markedly narrowed anteriorly; setae numerous, sockets raised; stemmata distinctly bulged laterally; labral fan stems well developed; 23 substantial labral fan rays; posteroventral arms of anal sclerite extended laterally to form wing-like lobes.

\section{Description}

Adult Female (Unknown)

Adult Male (Unknown) 
Pupa (based on pharate pupa)

Thorax: presence or absence of thoracic tubercles not determinable. Gill (Fig. 7): eight filaments; maximum length $2.0 \mathrm{~mm}$.

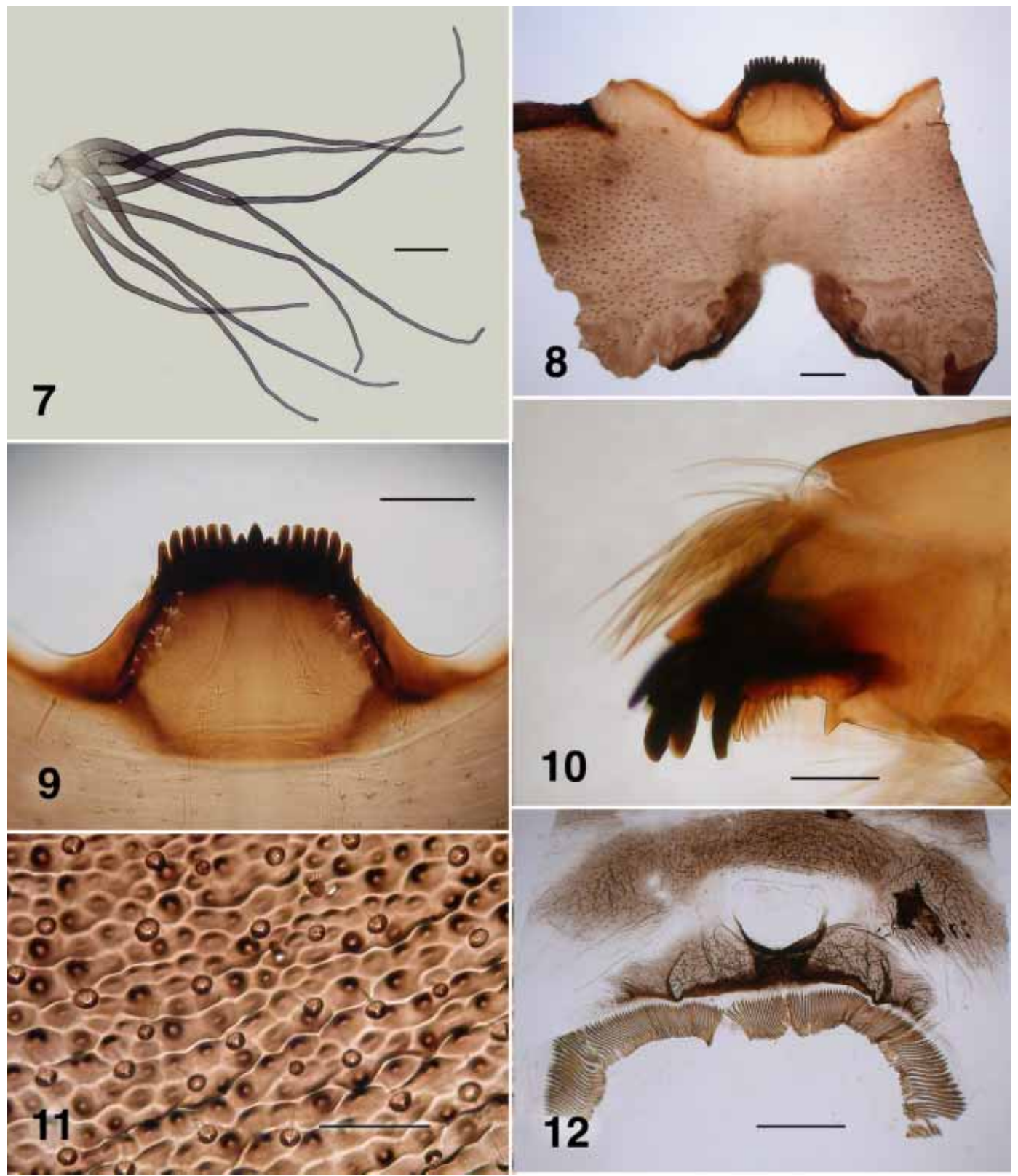

FIGURES 7-12. Simulium sublonckei. 7. Pupal gills. Scale bar $=0.2 \mathrm{~mm}$. 8. Hypostoma and postgenal cleft. Scale bar $=0.1 \mathrm{~mm}$. 9. Hypostomal teeth. Scale bar $=0.1 \mathrm{~mm}$. 10. Mandible. Scale bar $=0.05 \mathrm{~mm}$. 11. Posterodorsal abdominal cuticle. Scale bar $=0.05 \mathrm{~mm}$. 12. Anal sclerite. Scale bar $=0.2 \mathrm{~mm}$. 
Larva (based on six last instar larvae). Body: total length $6.5-7.6 \mathrm{~mm}$; colour dark brown dorsally, sharply delimited laterally, pale ventrally; pale median line on thorax. Head (Fig. 15): width $0.86-0.93 \mathrm{~mm}$, length $0.83-0.93 \mathrm{~mm}$; distance between fan-stem bases $0.42 \mathrm{~mm}$; colour evenly dark brown; head-spot pattern not obvious; frontoclypeal apotome narrowed posteriorly; head margins highly convex posteriorly, narrowed anteriorly, but not markedly; cervical sclerites fused to postocciput, but not to cephalic apotome; cuticle corrugated and slightly rugose; setae numerous, length normal, distinct dark raised sockets (Fig. 8). Antenna: evenly dark brown; $0.42 \mathrm{~mm}$ long; basal article curved, distal article $0.12 \mathrm{~mm}$ long, extended just beyond apex of labral-fan stem. Labral fan: stem brown and markedly hairy; 23 rays, $0.7 \mathrm{~mm}$ in length, brown, 2-3 posterolateral rays finer than others, medial rays $0.02 \mathrm{~mm}$ in width, microtrichia of medial rays 0.8 times ray width, pattern of longer microtrichia with 14-15 smaller ones, decreased abruptly in length to next long one, pattern very distinct, apex of ray markedly extended. Postgenal cleft (Fig. 8): markedly U-shaped, 0.6 times deep as wide; postgenal bridge 1.2 times longer than cleft depth. Hypostoma (Fig. 9): 15 teeth, median tooth subequal in length to other teeth; adjacent sublateral teeth smaller; other sublateral teeth peg-like, subequal in length, apices forming curved line laterally; lateral teeth not distinct; 1 paralateral tooth; 2 lateral serrations; 9-10 hypostomal setae per side, some bases closely situated. Mandible (Fig. 10): apical teeth heavily sclerotized and blunt; 8 substantial spinous teeth decreased abruptly in length to serration; serration basal width 1.2 times height, anterior convex edge 2.0 times longer than concave posterior edge; sensillum poorly developed. Mandibular phragma: extended ventrally to 0.3 of maxilla base. Maxilla: tapered, palpus $0.076 \mathrm{~mm}$ in length, $0.032 \mathrm{~mm}$ in basal width. Thorax: dark brown dorsally and laterally, median pale line anteriorly (Fig. 15); sternum pale. Abdomen: segments I-IV narrower than thorax, not increased in size posteriorly; segments V-VII increased gradually to maximum width at segment VII, then decreased smoothly. Posteroventral tubercles absent. Posterodorsal cuticle with closely-packed, small, dark brown tubercles; setae numerous with raised dark sockets (Fig. 11). Anal sclerite (Fig. 12): junction between anterior and posterior arms heavily pigmented and massive, anterior arms short and sharply tapered; posterolateral arms extended laterally to form heavily tuberculate, wing-like lobes, junction with accessory sclerite tenuous; accessory sclerite heavily pigmented and extended anteriorly to form anterolateral sclerite; posterolateral arms 4.0 times longer than anterolateral arms and extended 0.6 distance around posterior proleg; cuticle surrounding sclerite markedly setose. Posterior proleg circlet of hooks: with 163 rows of hooks, 25-27 hooks per row. Rectal papillae: complex.

\section{Additional material examined}

Tahiti-nui. Vaitamanu Vly Rd, 2nd cscd. 400 m. 11-viii-1996. Coll. D. A. and R. E. G. Craig; 27-vii-1998. Coll. D. A. Craig and D. A. Joy; 13-xi-2000. S17 47.72 ' W149 ${ }^{\circ}$ 11.47' Coll. D. A. and R. E. G. Craig (larvae. BPBM, DAC). Papenoo Valley, Marae cas- 
cade. 50 m. 26-vii-92. Coll. D. A. and R. E. G. Craig (larva. DAC). Vaihiria Valley, cas-

River. 445 m. 10-viii-1996. Coll. D. A. Craig and R. E. G. Craig (larvae. DAC).
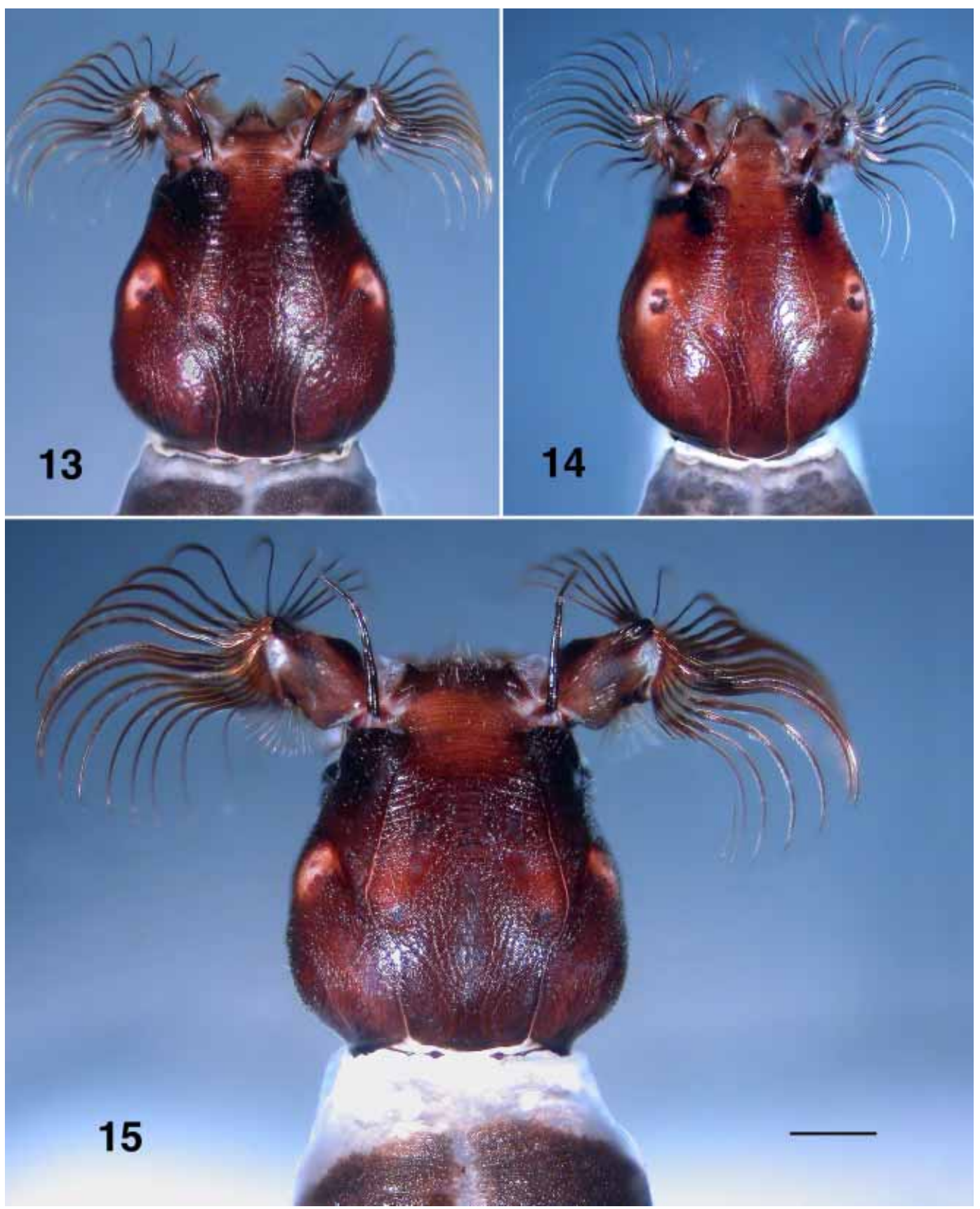

FIGURES 13-15. Larval heads. 13. Simulium lonckei (last instar). 14. S. joyae (penultimate instar). 15. S. sublonckei (last instar). Scale bar $=0.2 \mathrm{~mm}$. 
Tahiti-iti: $4 \mathrm{~km}$ west of Tautira, cascade. 4-iv-1988. Coll. D. A. Craig and S. Loncke

(larva. DAC). Fauoro Valley, Tirahi River, cascade. 40 m. 29-iv-88. Coll. D. A. Craig (larva. DAC). Vaitepiha River, cascade. 40 m. S17 46.61' W149 10.68'. 1-viii-1998. Coll. D. A. Craig and D. A. Joy (larvae. DAC).

\section{Etymology}

Named for its probable basal phylogenetic relationship to $S$. lonckei.

\section{Comments}

Larvae of S. sublonckei are similar in colouration and shape to those of S. lonckei and initially difficult to distinguish. Indeed, a misidentification was made by Craig (1997) where his Figure 63 is not of the larval head of S. lonckei, but is that of S. sublonckei. Further, the Vaitamanu locality given by Craig and Joy (2000) for S. lonckei is actually that for S. sublonckei. Larvae of both of these species are also similar to those of $S$. joyae (Fig 14), but they can be distinguished by the sharp lateral cut-off of the abdominal dorsal pigmentation and cuticular tubercles, the distinct pale ecdysial line on the anterior thorax, a broader anterior head, labral fans with more rays and a distinct medial hypostomal tooth. Simulium sublonckei with broader anterior and posterior cephalic apotome (cf. Figs. 1315), would appear to be the more plesiomorphic of these three related species.

Similar in habitat preference to S. lonckei and S. joyae, S. sublonckei is found only in cascades (Fig. 28). It occurs on both Tahiti-nui and Tahiti-iti, as does also S. joyae. At present, S. lonckei is known only from cascades on Tahiti-iti, a point of possible biogeographic significance.

The type locality cascade of $S$. sublonckei has been well collected over the years (e.g., Craig and Joy 2000, Craig 2001). With a preponderance of larvae of S. cataractarum, those of other species collected are $S$. arlecchinum, S. dussertorum, S. fararae, S. fossatiae, S. hirticranium, S. malardei, S. oviceps and S. neoviceps. With ten species this cascade has the greatest richness of any Tahitian locality (Craig 1997, 2001), however, in comparison to simuliid habitats elsewhere (Adler et al. 2004), it is not unusual.

\section{Simulium (Inseliellum) englundi n. sp.}

(Figs. 16-20, 22-26, 29).

Types

\section{Holotype}

Female: pinned. Label data—"Simulium (Inseliellum) englundi. MARQUESAS, Mohotani (Motane) Island, alt. 378 m. S9 ${ }^{\circ}$ 58.80’ W138 49.80'. 31-viii-2001. Coll. R. Englund, S. Jordan. HOLOTYPE. No. 16524" (BPBM). Head, mouthparts and genitalia cleared and in glycerine vial on pin. Thorax slightly damaged. Dried from alcohol via Peldri II ${ }^{\circledR}$. 
Larvae: Last and penultimate instars in alcohol. Label data as for Holotype, but with "PARATYPE" (BPBM).

\section{Diagnosis}

Adult female: markedly dark brown; vestiture of black hairs; maxillary palpus sensory vesicle poorly developed; posterolateral sclerite of anal fork markedly developed. Pupa: six gill filaments. Larva: head brown; labral fan stem markedly developed.

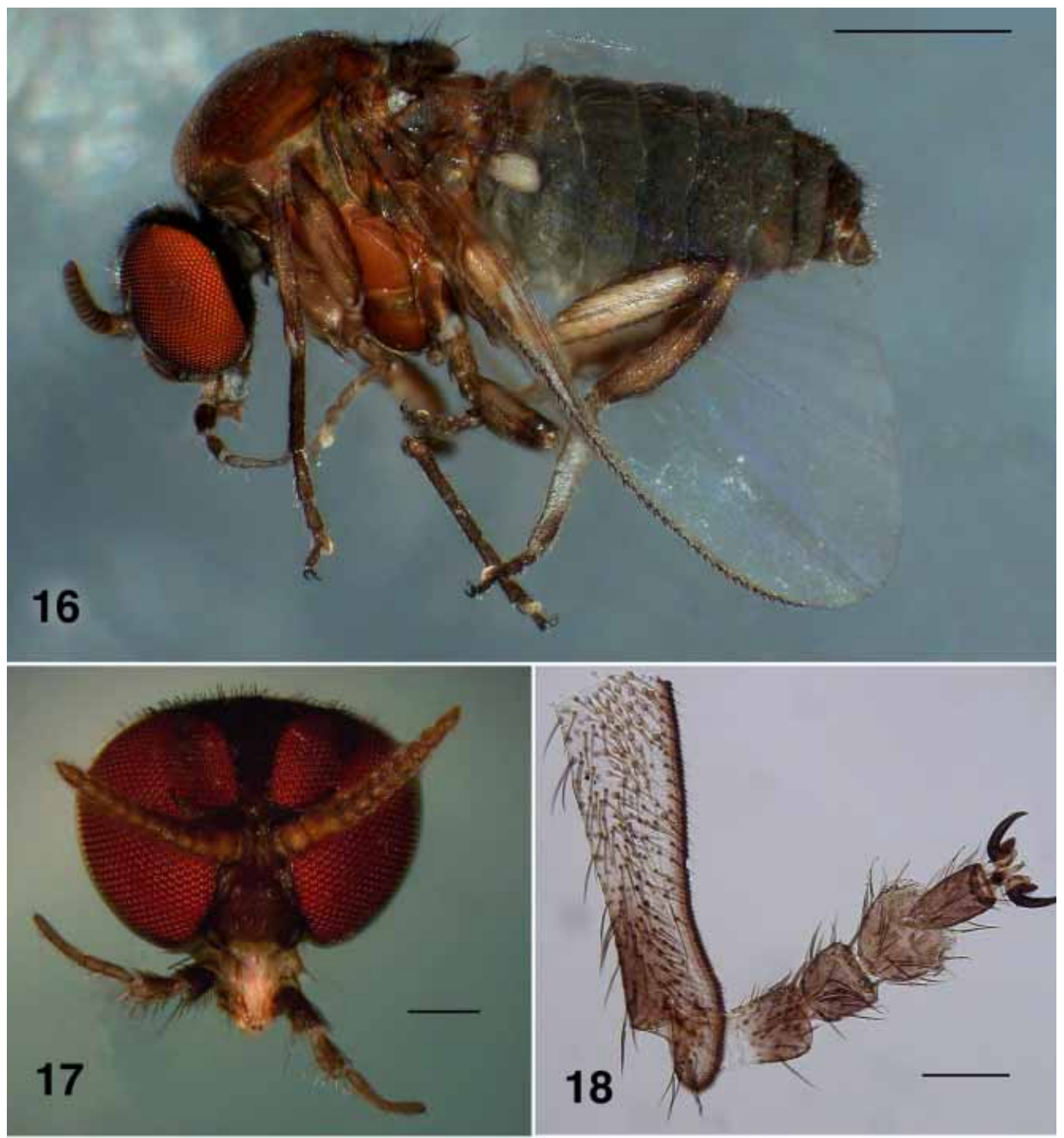

FIGURES 16-18. Simulium englundi. 16. Holotype female. Scale bar $=0.5 \mathrm{~mm}$. 17. Frontal view of Holotype head. Scale bar $=0.1 \mathrm{~mm}$. 18. Tip of left hind leg of Holotype showing calcipala, pedisulcus and pretarsal claws. Scale bar $=0.05 \mathrm{~mm}$. 


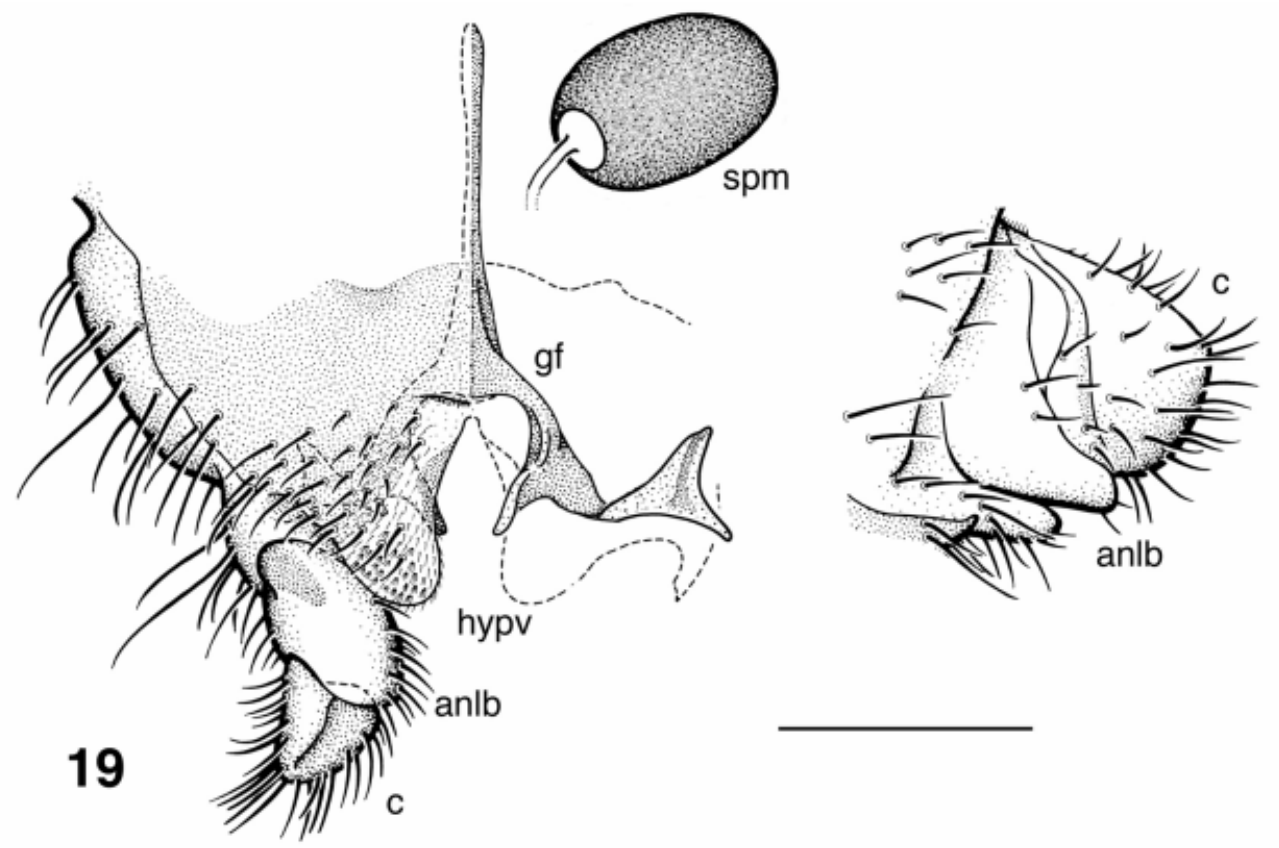

FIGURE 19. Simulium englundi. Female genitalia. Left-ventral view; right-lateral view of terminalia. Abbreviations: anlb—anal lobe; c_cercus; gf—genital fork; hypv—hypogynial valve; spm—spermatheca. Scale bar $=0.1 \mathrm{~mm}$.

\section{Description}

Adult Female (colours based on specimen in alcohol). Body (Fig. 16): overall medium to dark brown; $1.92 \mathrm{~mm}$ in length. Head (Fig. 17): eyes, dark red; postocciput, vertex and clypeus evenly dark brownish black; width $0.57 \mathrm{~mm}$, depth $0.44 \mathrm{~mm}$. Eyes: interocular distance $0.05 \mathrm{~mm}$; ommatidia $0.017 \mathrm{~mm}$ in diameter, ca. 28 and 30 respectively across and up eye in middle row. Frons: evenly dark brown, no apparent vestiture. Clypeus: slightly longer than wide, vestiture of sparse coarse black hairs. Post-ocular hairs: sparse, black, barely extended to eye margin. Antenna: total length $0.41 \mathrm{~mm}$; evenly dark brown. Mouthparts: 0.3 length of head depth; mandible poorly sclerotized, as long as labrum, 4 times as long as wide, 19 inner teeth; lacinia with 20-22 teeth; maxillary palpus $0.57 \mathrm{~mm}$ long, proportional lengths of 3rd, 4th and 5th articles, 1:1:3.1; sensory vesicle occupying 0.25 width of third article (markedly small), opening 0.3 width of vesicle; third article lacking markedly angular anterodistal margin; cibarium shallowly U-shaped, smooth between substantial, angular, heavily-pigmented proximal arms. Thorax: length $0.83 \mathrm{~mm}$, width $1.2 \mathrm{~mm}$; evenly dark brown; scutum lacking vittae, subshiny, vestiture of short black hairs; scutellum concolorous with scutum, apical angle of $90^{\circ}$, posterolateral edges slightly convex, vestiture of long coarse black hairs; postscutellum marginally lighter than scutellum, with darker medial region; pleuron evenly medium brown. Wing: length $1.7 \mathrm{~mm}$, width $0.8 \mathrm{~mm}$; veins generally very pale; stem vein hair tuft sparse. Halter: knob and pedicel pale. Legs (Fig. 16): coxae light brown; femora with main length yel- 
low, darker distal region; tibiae darker; hind tibiae mainly yellow; tarsi dark; calcipala well developed (Fig. 18); pretarsal claw with well developed basal tooth. Abdomen: overall dark gray with vestiture of fine black hairs; basal fringe of sparse black hairs extended to second abdominal segment; tergites marginally lighter than tergum; posterior tergites subshiny; sternum evenly gray, except for segment VIII which is concolorous with tergum. Genitalia (Fig. 19): cercus in lateral view flattened dorsally, convex ventrally; anal lobe extended only to base of cercus, with hairs ventromedially; hypogynial valves distinctly rounded apically, extended 0.3 length of anal lobe, with sparse vestiture of short hairs and trifid microtrichia laterally; median space extended anteriorly to branch of genital fork, narrowly rounded anteriorly, slightly wider at mid-depth, pigmented area at mid-depth; stem of genital fork narrow, with accessory fluted lobe posteromedially; posterolateral triangular sclerite markedly enlarged, with medial ridge. Spermatheca: ovoid, dark brown, pattern and internal hairs absent, distinct clear area at spermathecal duct junction.

Adult Male (Unknown)

Pupa (based on pharate gill histoblasts)

Gill (Fig. 20): six fine filaments $(3+1+2) ; 1.8 \mathrm{~mm}$ maximum length; filaments subequal in length.

Larva (Based on four last instar larvae with dark pharate pupal gills).

Body: evenly medium gray; total length 4.7-4.9 mm. Head (Fig. 22): colour overall light brown; width $0.54 \mathrm{~mm}$, length $0.58 \mathrm{~mm}$; distance between fan stem bases $0.35 \mathrm{~mm}$; lateral margins slightly convex, more so posteriorly; frontoclypeal apotome pale brown anteriorly, darker posteromedially with marked figure 8 -shaped pattern produced by negative head spots, cuticle lateral of ecdysial line brown, lateral pigmentation medium brown; cervical sclerites small but distinct, not fused to postocciput. Antenna: essentially unpigmented; total length $0.51 \mathrm{~mm}$; distal article $0.17 \mathrm{~mm}$ in length, complete article extended well beyond apex of labral fan stem. Labral fans: stem markedly elongated (cf. Figs. 21, 22); 27-31 rays, medial rays $1.06 \mathrm{~mm}$. in length; width $0.01 \mathrm{~mm}$; microtrichia 1.3 times longer than ray width, longer microtrichia with 4-5 smaller ones decreased slightly in size to next long one. Postgenal bridge (Fig. 23): two times longer than cleft depth; colour pale. Postgenal cleft: shallow V-shaped, two times as wide as deep, with small anterior extension. Hypostoma (Fig. 24): 12-13 teeth; median tooth prominent, just extended beyond lateral teeth; 3 sublateral teeth; 1-2 paralateral teeth; 2 very small lateral serrations; 4-5 hypostomal setae per side. Mandible (Fig. 25): apical teeth well developed; seven spinous teeth; distance between spinous teeth and serration marked; serration longer than basal width, curved; sensillum distinct; cuticle posterior to sensillum smooth and convex. Maxilla: tapered; palpus 2.5 times as long as basal width. Mandibular phragma: extended ventrally to 0.3 depth of maxilla base. Abdomen: anteriorly concolourous gray with thorax, expanded posterior segments browner; segments I-IV subequal in size to thorax, expanded gradually at segment V, and further to segment VII, then decreased gradually (elongated amphora-shape); posteroventral tubercles small, but distinct; posterodorsal cuticle with no 
obvious cuticular pattern. Anal sclerite (Fig. 26): posteroventral arms subequal in length to dorsolateral arms, well separated from lateral accessory sclerites. Posterior proleg circlet of hooks: with 71 rows of hooks, $12-14$ hooks per row. Rectal papillae: simple.

\section{Etymology}

Named after R. Englund, who collected the material.

\section{Comments}

Simulium englundi larvae are similar in many characters to those of S. gallinum (Fig. 21 ) and $S$. hukaense, but differ in darker head coloration, postgenal cleft shape, more pronounced hypostomal teeth and longer labral fan stem. The female differs markedly from that of S. gallinum (Hiva Oa) in darker colour and vestiture and the lateroposterior triangular sclerite of the genital fork which is markedly enlarged. The pupa has six gill filaments of pattern similar to that in S. hukaense. With poorly sclerotized mandibles and undeveloped maxillary palpus sensory vesicle, it is unlikely that females of $S$. englundi blood feed.

Mohotani, $15 \mathrm{~km}$ directly south of Hiva Oa, is a small $\left(12.2 \mathrm{~km}^{2}\right)$ volcanic island with coastal cliffs and a gentle sloping interior, that reaches an altitude of $520 \mathrm{~m}$. The type locality of $S$. englundi is a small stream on the northern side of the island, starting as a trickle at $390 \mathrm{~m}$ altitude and is only some $400 \mathrm{~m}$ in length. The only permanent running water on the island, the stream consists of small cascades 3-4 $\mathrm{m}$ in height (Fig. 29), interspersed with pools. As typical for Marquesan simuliid larvae (Craig 2001), those of $S$. englundi were taken off leaves only.

Mohotani has feral sheep and the undergrowth is severely over-grazed causing considerable erosion. Craig (2003) discussed conservation of Polynesian simuliids, noting that most running water in Polynesia has been impacted by humans in one manner or another. He concluded, however, that on the larger islands (e.g., Tahiti) that there were still pristine habitats available for simuliids. But, for Mohotani, S. englundi, might be considered an endangered species, since there is only the one small stream.

\section{Discussion}

The majority of new species of Tahitian Inseliellum described by Craig (1997) and Craig and Joy (2000) have been from higher altitude localities and so are the two new species described herein. Noticeable also is that the new species have characteristics that tend to bridge the limits of previous established species groups. Perhaps this should be expected since the fauna is young and apparently rapidly evolving (Craig 2003, Joy et al. 2004) and the basal progenitor species are still extant (Craig and Currie 1999, Craig et al. 2001). As noted by Craig (1997), it is becoming more apparent that there are seasonal differences in species composition from a given stream, particularly those of higher altitude. The $S$. sublonckei type locality has been collected extensively; however, typically during the Austral winter. The most recent collection was in the Austral summer and S. sublonckei larvae were markedly more numerous, while those of some species such as $S$. fararae, collected from that site during winter, were absent. 

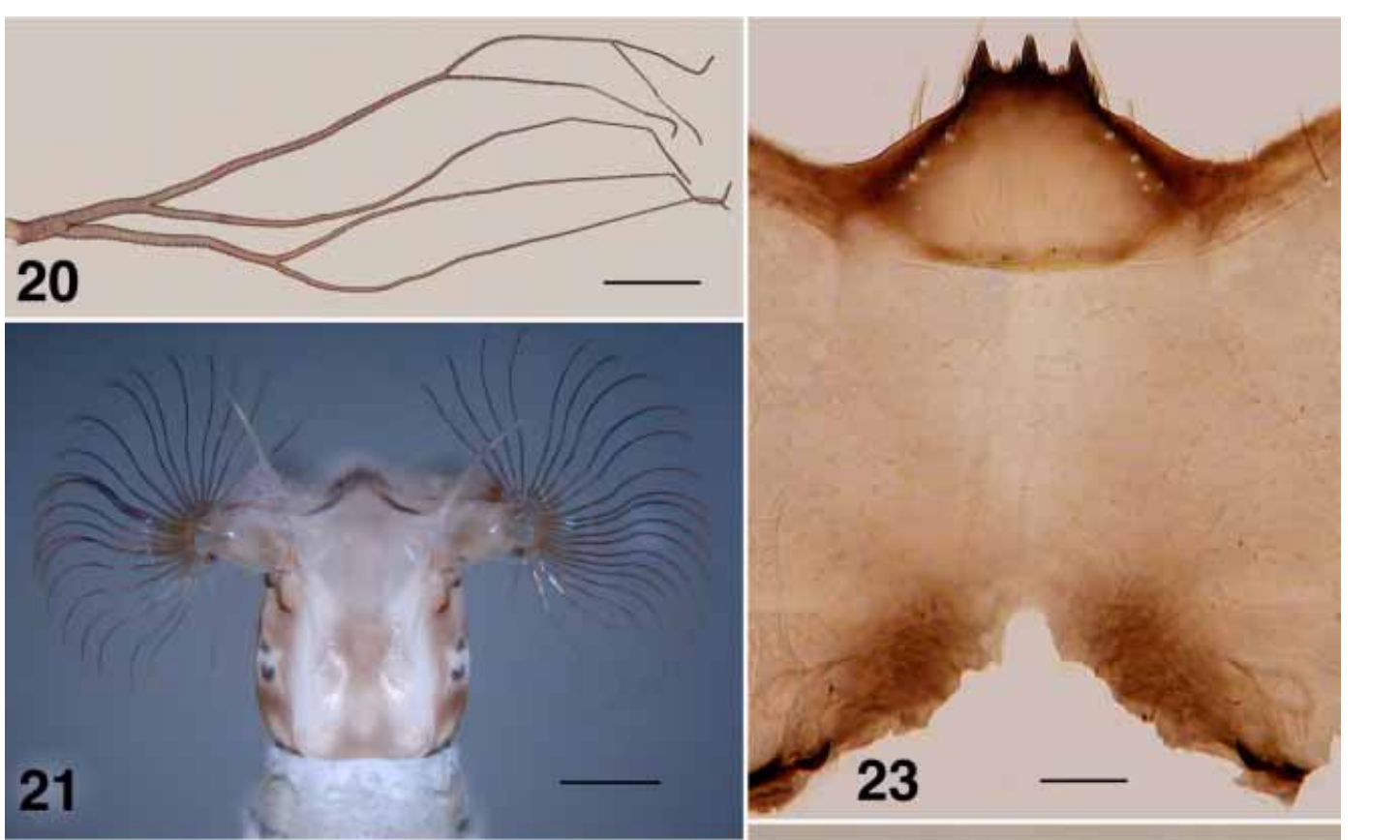

ZOOTAXA
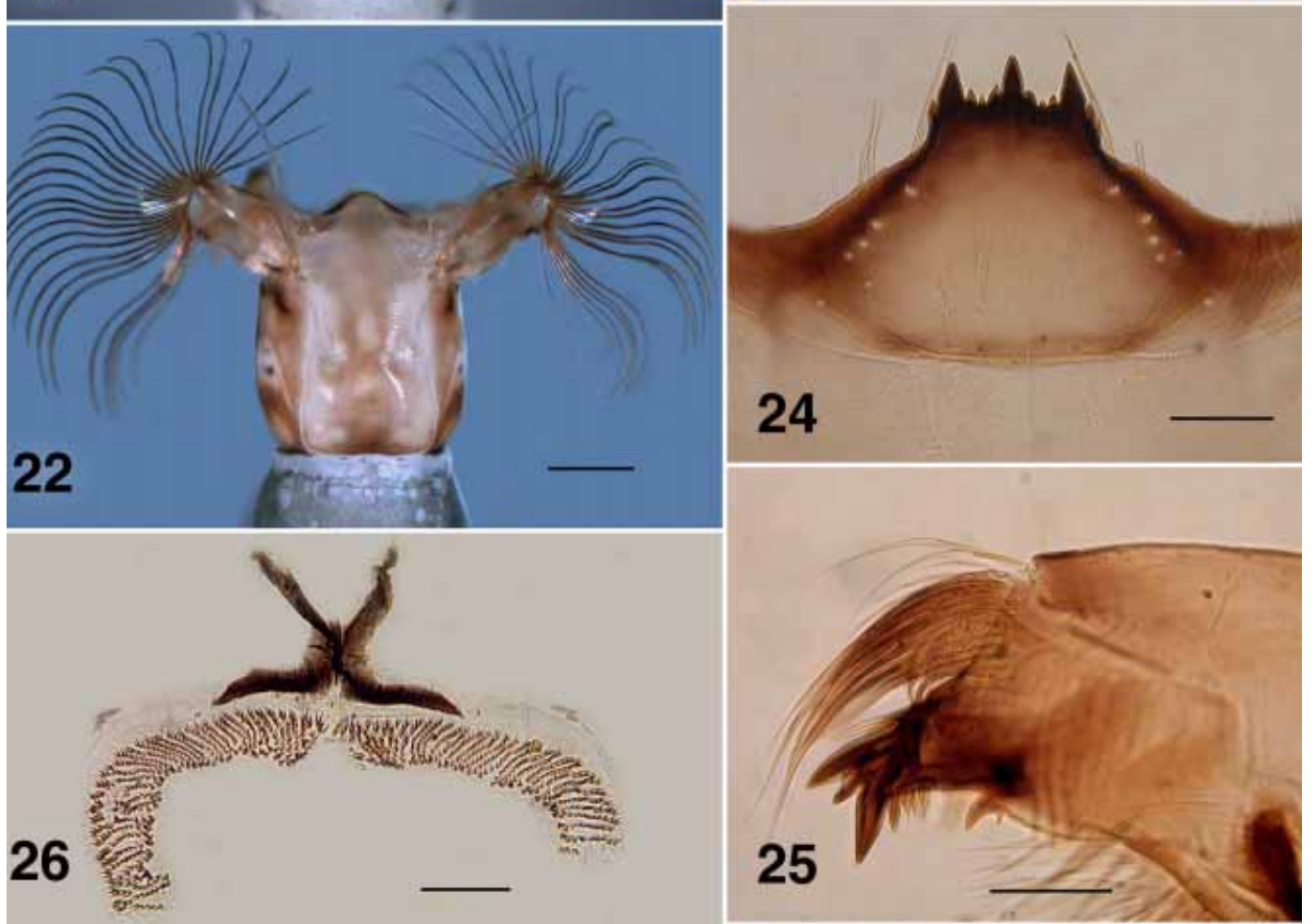

FIGURE 20. Simulium englundi, pupal gill filaments. Scale bar $=0.2 \mathrm{~mm}$. FIGURE 21. $S$. gallinum (Hiva Oa), last instar larval head. Scale bar $=0.25$ mm. FIGURES 22-26. S. englundi. 22. Last instar larval head. Scale bar $=0.25 \mathrm{~mm}$. 23. Hypostoma and postgenal cleft. Scale bar $=0.05$ mm. 24. Hypostomal teeth. Scale bar $=0.05 \mathrm{~mm}$. 25. Mandible. Scale bar $=0.05 \mathrm{~mm}$. 26. Anal sclerite. Scale bar $=0.1 \mathrm{~mm}$. 


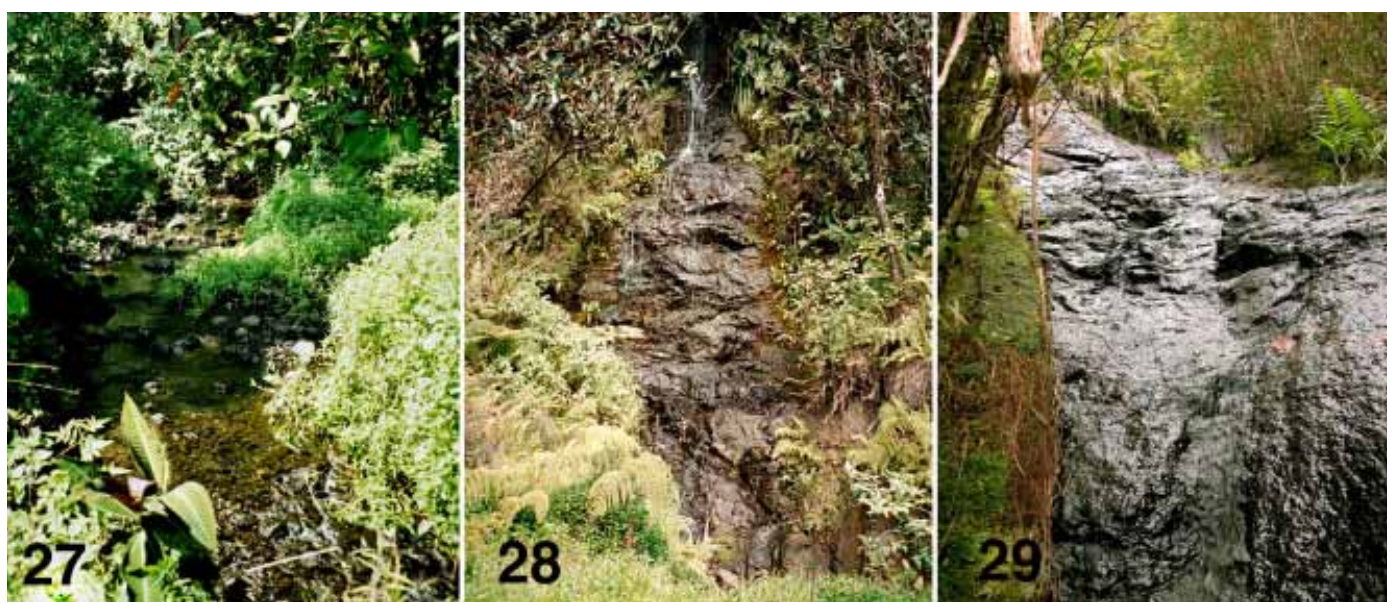

FIGURES 27-29. Type localities. 27. Simulium adelaideae. Above Lac Vaihiria on cross-Tahiti road. Larva collected in densely-shaded portion of stream in background. 28. S. sublonckei. Second cascade on road to Maroto River barrage, Vaitamanu Valley, Papenoo River catchment. 29. $S$. englundi. Unnamed stream, Mohotani Island, Hiva Oa, Marquesas Islands. Photograph courtesy of R. Englund.

The occurrence of an endemic species of simuliid (S. englundi) on such a small island as Mohotani is unexpected, given that the distance between that island and Hiva Oa is only $15 \mathrm{~km}$. MacArthur and Wilson (1963) hypothesized that adaptive radiation within an island would be a major contributor to species richness, and that this may increase on islands of major distance from the source. Their rationale was that colonization to a far island, although rare, might allow colonists to be less influenced by gene flow from the source populations which would hinder speciation. For example, Moorea, presumably close enough $(21 \mathrm{~km})$ to Tahiti to be influenced by gene flow from Tahitian species, has not undergone an intra-island species radiation, and while possess 10 species, has only one poorly known endemic species (Craig and Joy 2000). Raiatea, the second largest of the Society Islands and well removed $(200 \mathrm{~km})$ from Tahiti, has had a moderate intra-island species radiation (4 endemic species), but was close enough to Tahiti for some colonization (3 species) (Craig 2003, Spironello and Brooks 2003).

Geologically the average age of Mohotani $(2.15 \mathrm{My})$ is little different from that of Tahuata (1.91 My), merely $23 \mathrm{~km}$ to the west, or the larger island of Hiva Oa (1.91 My) just to the north (15 and $5 \mathrm{~km}$ respectively) of both of them (Clouard and Bonneville 2001). Simulium gallinum is widespread in the Marquesas (Craig et al. 1995) and is assumed to be basal to other Marquesan species (Craig and Currie 1999, Craig et al. 2001), so without further information, it is not unreasonable to assume that $S$. englundi diverged from a $S$. gallinum precursor after the latter had arrived at this group of islands. Speciation appears to have occurred rapidly on Mohotani, since this small island, apart from possessing an endemic simuliid species, has other endemic biota. Ixora marquesas (Rubiaceae) is 
endemic to Mohotani, with Lebrannecia kakiodes (Malvaceae) endemic to Mohotani and Tahuata. Further, Mohotani has two endemic subspecies of birds: Pomarea medozae montanensis (Flycatcher) and Acrocephalus caffer consobrinus (Polynesian Warbler).

Does this endemism on such a small island, close to a larger one, indicate that interisland gene flow for Marquesas simuliids is lower than that apparent for those of the Society Islands (Craig et al. 2001)? As noted by Craig (2003), there is still much to be learned about the Polynesian Simuliidae. In particular, the Marquesas simuliids are in need of cytological and molecular scrutiny to compliment the preliminary morphological-based study by Craig et al. (1995).

\section{Acknowledgement}

Grant No. 5753 from the Natural Sciences and Engineering Research Council of Canada supported this work.

\section{References}

Adler, P.H., Currie, D.C. \& Wood, D.M. (2004) The Black Flies (Simuliidae) of North America. Cornell University Press, Ithaca, New York, 941 pp.

Clouard, V. \& Bonneville, A. (2001) How many Pacific hotspots are fed by deep-mantle plumes? Geology, 29, 695-698.

Craig, D.A. (1983) Phylogenetic problems in Polynesian Simuliidae (Diptera: Culicomorpha): a progress report. GeoJournal, 7, 533-541.

Craig, D.A. (1987) A taxonomic account of the black flies (Diptera: Simuliidae) of the Society Islands-Tahiti, Moorea, Raiatea. Quaestiones Entomologicae, 23, 372-429.

Craig, D.A. (1997) A taxonomic revision of the Pacific black fly subgenus Inseliellum (Diptera: Simuliidae). Canadian Journal of Zoology, 75, 855-904.

Craig, D.A. (2001) Report on collecting trip to Polynesia to obtain black flies (Simuliidae). Report prepared for Mission des infrastructures du Développement et de la Coopération Régional, Papeete, Tahiti. 14 pp.

Craig. D.A. (2003) Geomorphology, development of running water habitats and evolution of black flies on Polynesian islands. BioScience, 53, 1079-1093..

Craig, D.A. \& Craig, R.E.G. (1986) Simuliidae (Diptera: Culicomorpha) of Rarotonga, Cook Islands, South Pacific. New Zealand Journal of Zoology, 13, 357-366.

Craig, D.A. \& Currie, D.C. (1999) Phylogeny of the western-central Pacific subgenus Inseliellum (Diptera: Simuliidae). Canadian Journal of Zoology, 77, 610-623.

Craig D.A., Currie, D.C. \& Joy, D.A. (2001) Geographical history of the central-western Pacific black fly subgenus Inseliellum (Diptera: Simuliidae: Simulium) based on a reconstructed phylogeny of the species, hot-spot archipelagos, and hydrological considerations. Journal of Biogeography, 28, 1101-1128.

Craig, D.A., Fossati, O. \& Séchan, Y. (1995) Black flies (Diptera: Simuliidae) of the Marquesas Islands, French Polynesia: redescriptions and new species. Canadian Journal of Zoology, 73, 775-800. 
Craig, D.A. \& Joy, D.A. (2000) New species and some redescriptions in the central-western Pacific subgenus Inseliellum (Diptera: Simuliidae). Annals of the Entomological Society of America, 93, 1236-1262.

Joy, D.A., Craig, D.A. \& Conn, J.E. (2004) Mitochondrial DNA divergence and larval ecology of the island black flies Simulium oviceps and Simulium dussertorum. Molecular Ecology (in press).

MacArthur, R.H. \& Wilson, E.O. (1963) An equilibrium theory of insular zoogeography. Evolution, $17,373-387$.

Spironello, M.\& Brooks, D.R. (2003) Dispersal and diversification: macroevolutionary implications of the MacArthur-Wilson model, illustrated by Simulium (Inseliellum) Rubtsov (Diptera: Simuliidae). Journal of Biogeography, 30, 1563-1573. 